ADLFI. Archéologie de la France -

INFORMATIONS Informations

une revue Gallia

Aquitaine | 2008

\title{
Mauléon-Licharre - Le Château
}

\section{Anne Berdoy}

Édition électronique

URL : http://journals.openedition.org/adlfi/2669

ISSN : 2114-0502

Éditeur

Ministère de la culture

\section{Référence électronique}

Anne Berdoy, "Mauléon-Licharre - Le Château », ADLFI. Archéologie de la France - Informations [En ligne], Aquitaine, mis en ligne le 01 mars 2008, consulté le 21 avril 2019. URL : http:// journals.openedition.org/adlfi/2669

Ce document a été généré automatiquement le 21 avril 2019

(c) Ministère de la Culture et de la Communication, CNRS 


\section{Mauléon-Licharre - Le Château}

\section{Anne Berdoy}

\section{Identifiant de l'opération archéologique : 025366}

Date de l'opération : 2008 (RA)

1 La perspective de travaux de sécurisation et de mise en valeur du château de MauléonLicharre a donné lieu, préalablement, à la réalisation d'un état des connaissances. Celui-ci a conduit notamment à replacer l'édifice dans son contexte et à réviser les datations proposées jusqu'alors.

2 L'histoire du château est documentée à partir de 1122, lorsqu'un acte d'Alphonse le Batailleur est donné dans le « château nouveau » du chef-lieu de la vicomté de Soule. Celui-ci fut-il édifié à l'emplacement du château antérieur ou y a-t-il eu déplacement par rapport au premier château vicomtal ? Si les deux hypothèses peuvent être défendues, il est toutefois impossible de trancher en l'état. L'histoire de l'occupation du sol permet en revanche de noter la mise en place d'un habitat subordonné au château (la " haute ville » actuelle), à quelque distance de l'église paroissiale Saint-Jean de Berraute. Pour pallier l'inconvénient de cette distance, le castrumfut doté d'une chapelle au XIV $\mathrm{s}$.

Du château du XII ${ }^{e}$ s., passé au roi d'Angleterre au XIII ${ }^{e}$ s. puis au vicomte de Béarn au XV ${ }^{e}$ s., il ne reste guère que quelques assises de pierre. Plusieurs épisodes guerriers et, surtout, le rattachement définitif de la Soule à la couronne de France dans les années 1510, ont conduit à de profondes modifications de la forteresse médiévale. Au cours de la première moitié du XVI ${ }^{e}$ s., la construction de tours d'artillerie et d'un fort bastion doté de canonnières a permis d'adapter l'architecture du château à l'évolution de la poliorcétique. Totalement remodelé au début de l'époque moderne, le château de Mauléon n'entrait plus en revanche au XVII ${ }^{\mathrm{e}} \mathrm{s}$. dans le dispositif des forteresses royales. Il fut en grande partie démantelé en 1642 avant d'être reconstruit quelques années plus tard. 
4 Au final, quelques points méritent d'être mis en exergue. À l'échelle de Mauléon, le château est indissociable du bourg fondé à ses pieds, qui lui a été subordonné et qui a fait partie de son système défensif.

5 À l'échelle de la Soule, le château est la traduction matérielle d'une partie du pouvoir des vicomtes à l'époque médiévale. Par son réaménagement à l'époque moderne il a contribué à symboliser le pouvoir royal jusqu'à sa « déchéance ».

6 Démoli puis reconstruit, il a enfin été « libéré » de sa fonction militaire en un temps où la frontière s'est déplacée. Le château de Mauléon est bien in capo de Sobola(selon les termes de l'acte de 1122), et son histoire témoigne de celle de la Soule tout entière.

7 Enfin, les vicissitudes de cette histoire sont inscrites dans l'architecture même du château:l'époque moderne a fait table rase ou presque de l'édifice médiéval et les élévations actuelles lui sont majoritairement attribuables. Ce réaménagement lié à l'artillerie à poudre ainsi que la place occupée par le château de Mauléon dans le dispositif défensif régional mériteraient de faire l'objet de recherches plus approfondies.

Berdoy Anne

\section{INDEX}

operation Relevé architectural (RA)

Index géographique : Aquitaine, Pyrénées-Atlantiques (64), Mauléon-Licharre

Thèmes : canon (arme), chapelle, château, église, forteresse, guerre, habitat, tour défensive

Index chronologique : Moyen Âge, Temps Modernes

\section{AUTEURS}

\section{ANNE BERDOY}

EP 